\title{
Bilateral sixth cranial nerve palsy in infectious mononucleosis
}

\author{
JAMES NEUBERGER* \\ M.A., B.M., B.Ch., M.R.C.P. \\ IAN BONE \\ M.B., Ch.B., M.R.C.P.
}

St James's University Hospital, Leeds LS9 7TF

\begin{abstract}
Summary
A 15-year-old girl who presented with a bilateral sixth nerve palsy caused by infectious mononucleosis is described. The neurological presentation of infectious mononucleosis is discussed.
\end{abstract}

\section{Introduction}

Infectious mononucleosis is a common disorder of childhood and adolescence. Johansen (1941) first described neurological involvement in infectious mononucleosis, and the incidence of neurological disturbance has been variously estimated at $0.7 \%$ (Rugg-Gunn, 1954) to 7\% (Gautier-Smith, 1965) of all patients usually diagnosed as aseptic meningitis. It is rare for the neurological complication to be the dominant or presenting feature. A case of infectious mononucleosis who presented with bilateral sixth nerve palsy is reported.

\section{Case report}

A 15-year-old schoolgirl consulted her family doctor because of an upper respiratory tract infection and swollen eyes; her boy friend had recently had a similar illness. She was treated with cotrimoxazole, 2 tablets twice daily, and linctus codeine compound. Six days later she developed a rash on her trunk, thought to be due to a drug allergy, for which she was treated with chlorpheniramine, $4 \mathrm{mg}$ 4 times a day for 4 days. On the fourteenth day of her illness she developed diplopia on lateral gaze and was referred to the Neurology Clinic where she was seen the following day.

On examination she was well and apyrexial. A faint morbilliform rash was evident, maximal over the trunk. The throat and fauces were normal: there was no lymphadenopathy nor splenomegaly. In the nervous system, the only abnormality was a bilateral sixth nerve palsy; there was no evidence of meningism. Investigations showed haemoglobin $13.3 \mathrm{~g} / \mathrm{dl}$, white cell count $8.0 \times 10^{9} / 1(56 \%$ lymphocytes, $39 \%$

\footnotetext{
*Present address: Liver Unit, King's College Hospital, Denmark Hill, London SE5 9RS.
}

neutrophils, $5 \%$ monocytes). There were atypical lymphocytes; the Paul Bunnell and monospot tests were positive. Four days later the diplopia began to improve and after one week had cleared completely.

\section{Discussion}

Neurological involvement may precede or accompany a clinical attack of infectious mononucleosis and present a meningoencephalitis, encephalitis, Guillain-Barré syndrome, spinal involvement, cranial nerve palsy, peripheral neuropathy (Silverstein, Steinberg and Nathanson, 1972), cerebellar disturbance (Bergen and Grossman, 1975), or retrobulbar neuritis (Pickins and Sangsten, 1975). Bernstein and Wolff (1950) reviewed this subject and found neurological involvement was not an uncommon presenting feature in infectious mononucleosis, whilst Schnell and colleagues (1966) surveying a selected group of 12 patients with infectious mononucleosis who were seen in the section of Neurology, found that none of the patients presented with neurological complications. In 1972 Silverstein et al. reviewed 144 patients with infectious mononucleosis from the Mount Sinai Hospital, and found neurological involvement was the major or presenting feature in $\mathbf{1 5}$ of the patients. They also reviewed a further 8 patients from the literature. In all but one of these patients headache was a feature, and none of these patients was so mildly affected as the present patient. Since then, Yahr has reported 2 patients, one presenting with an autonomic neuropathy and one with chorea (Yahr and Frontera, 1975). Davidson and Salter (1964) described a woman with infectious mononucleosis who presented with facial diplegia, although she also had diabetes mellitus.

Bilateral sixth nerve palsy in an otherwise well person is rare. Keane (1976) has recently reviewed 125 consecutive patients with bilateral sixth nerve palsy. Infection was the cause in only 12 of them, this taking the course of diffuse and parameningeal infection, and in 9 cases the palsy was associated 
with the polyneuropathy of Guillain-Barré. Though bilateral sixth nerve palsy has been described in infectious mononucleosis (Silverstein et al., 1972), all were associated with other signs of brain stem involvement.

The neurological involvement usually has few sequelae and the deficit clears, but fatalities do occur. Indeed, neurological complications are second only to splenic rupture as a cause of death in these patients. Post-mortem studies have shown atypical mononuclear infiltration, perivascular cuffing around small blood vessels with cellular degeneration (Friedland and Yahr, 1977). It has been established (Joncas, 1972) that Epstein-Barr (EB) virus is the causative agent of infectious mononucleosis and EB virus antibodies have been found in the cerebrospinal fluid of patients with neurological involvement in infectious mononucleosis (Joncas et al., 1974). Friedland and Yahr (1977) have suggested that the rapid reversibility of the neurological deficit may imply an underlying immunological mechanism rather than 'neuraxitis'. The association of EB virus with the Guillain-Barré syndrome (Currie, 1975) might also support an immune disturbance.

This case is reported to demonstrate that neurological dysfunction may be the sole or presenting feature of infectious mononucleosis. It usually has a good prognosis. Infectious mononucleosis should always be considered in an adolescent who presents with any acute neurological deficit, even if there is no evidence clinically of any systemic disease.

\section{Acknowledgment}

We thank Dr D. W. Sumner for permission to report a patient under his care.

\section{References}

Bernstein, T.C. \& WolfF, H.C. (1950) Involvement of the nervous system in infectious mononucleosis. Annals of Internal Medicine, 33, 1120.

Bergen, D. \& Grossman, H. (1975) Acute cerebellar ataxia associated with infectious mononucleosis. Journal of Pediatrics, 87, 832.

CURRIE, S.C. (1975) In: Modern Trends in Neurology (Ed. by D. Williams), vol. 6, p. 23. Butterworths, London.

Davidson, R.S.L. \& Salter, R.H. (1964) Infectious mononucleosis presenting with facial diplegia. British Medical Journal, 1, 954.

Friedland, R. \& YAHR, M.D. (1977) Meningoencephalopathy secondary to infectious mononucleosis. Archives of Neurology, 34, 186.

Gautier-SMith, P.C. (1965) Neurological complications of glandular fever. Brain, 88, 323.

Johansen, A.H. (1931) Serous meningitis and infectious mononucleosis. Acta medica scandinavica, 76, 269.

JoNCAS, J.H. (1972) Clinical significance of Epstein-Barr virus in man. Progress in Medical Virology, 14, 200.

Joncas, J.H., Chicoine, L., Thivierge, R. \& Bertrand, M. (1974) Epstein-Barr virus antibodies in the cerebrospinal fluid. American Journal of Diseases in Childhood, 217, 282.

KEANE, J.R. (1976) Bilateral sixth nerve palsy. Archives of Neurology, 33, 68.

Pickins, S. \& SANGsten, G. (1975) Retrobulbar neuritis with infectious mononucleosis. British Medical Journal, 4, 729.

RugG-GunN, M.A. (1954) Infectious mononucleosis. Proceedings of the Royal Society of Medicine, 47, 759.

SchNell, R.C., Dick, P.J., BowIE, E.J.W., Klass, D.W. TASWELL, H.F. (1966) Infectious mononucleosis: neuro logic and electroencephalographic findings. Medicine 45, 51.

Silverstein, A., Steinberg, G. \& Nathanson, M. (1972) Nervous system involvement in infectious mononucleosis. Archives of Neurology, 26, 353.

YAHR, M.D. \& Frontera, A.T. (1975) Acute autonomic neuropathy: its occurrence in infectious mononucleosis. Archives of Neurology, 32, 132. 